Special issue contribution ESCDD 2018

\title{
Biocompatible bacteria-derived vesicles show inherent antimicrobial activity
}

Eilien Schulz ${ }^{1,2}$, Adriely Goes ${ }^{1,2}$, Ronald Garcia ${ }^{3,4}$, Fabian Panter ${ }^{3}$, Marcus Koch ${ }^{5}$, Rolf Müller ${ }^{2,3,4}$, Kathrin Fuhrmann ${ }^{1}$ and Gregor Fuhrmann ${ }^{1,2 *}$

${ }^{1}$ Helmholtz Institute for Pharmaceutical Research Saarland (HIPS), Helmholtz Centre for Infection Research (HZI), Biogenic Nanotherapeutics group (BION), Campus E8.1, 66123 Saarbrücken

${ }^{2}$ Department of Pharmacy, Saarland University, Campus E8.1, 66123 Saarbrücken, Germany

${ }^{3}$ Helmholtz Institute for Pharmaceutical Research Saarland (HIPS), Helmholtz Centre for Infection Research (HZI), Department of Microbial Natural Products (MINS), Campus E8.1, 66123

Saarbrücken

${ }^{4}$ German Center for Infection Research (DZIF), Partner site Hannover-Braunschweig 38124, Germany

${ }^{5}$ INM - Leibniz Institute for New Materials, Campus D2 2, 66123, Saarbrücken, Germany

*Corresponding author, phone: +49 68198806 1500, email: gregor.fuhrmann@helmholtz-hzi.de

ORCID IDs: Eilien Schulz: 0000-0002-9769-8980, Adriely Goes: 0000-0003-2629-6068; Fabian Panter: 0000-0002-1783-6803; Rolf Müller: 0000-0002-1042-5665; Kathrin Fuhrmann: 0000-00025599-9718; Gregor Fuhrmann: 0000-0002-6688-5126

Keywords: outer membrane vesicles; extracellular vesicles; biogenic drug carriers; nanoantibiotics; myxobacteria; electron cryomicroscopy 


\section{Abstract}

Up to 25,000 people die each year from resistant infections in Europe alone, with increasing incidence. It is estimated that a continued rise in bacterial resistance by 2050 would lead up to 10 million annual deaths worldwide, exceeding the incidence of cancer deaths. Although the design of new antibiotics is still one way to tackle the problem, pharmaceutical companies investigate far less into new drugs than 30 years ago. Incorporation of antibiotics into nanoparticle drug carriers ("nanoantibiotics") is currently investigated as a promising strategy to make existing antibiotics regain antimicrobial strength and overcome certain types of microbial drug resistance. Many of these synthetic systems enhance the antimicrobial effect of drugs by protecting antibiotics from degradation and reducing their side effects. Nevertheless, they often cannot selectively target pathogenic bacteria and - due to their synthetic origin - may induce side-effects themselves.

In this work, we present the characterisation of naturally derived outer membrane vesicles (OMVs) as biocompatible and inherently antibiotic drug carriers. We isolated OMVs from two representative strains of myxobacteria, Cystobacter velatus Cbv34 and Sorangiineae species strain SBSr073, a bacterial order with the ability of lysing other bacterial strains and currently investigated as sources of new secondary metabolites. We investigated the myxobacterias' inherent antibacterial properties after isolation by differential centrifugation and purification by size-exclusion chromatography. OMVs have an average size range of 145-194 $\mathrm{nm}$. We characterised their morphology by electron cryomicroscopy and found that OMVs are biocompatible with epithelial cells and differentiated macrophages. They showed a low endotoxin activity comparable to those of control samples, indicating a low acute inflammatory potential. In addition, OMVs showed inherent stability under different storage conditions, including $4{ }^{\circ} \mathrm{C},-20{ }^{\circ} \mathrm{C},-80{ }^{\circ} \mathrm{C}$ and freeze-drying. OMV uptake in Gram-negative model bacterium Escherichia coli (E. coli) showed similar to better incorporation than liposome controls, indicating the OMVs may interact with model bacteria via membrane fusion. Bacterial uptake correlated with antimicrobial activity of OMVs as measured by growth inhibition of E. coli. OMVs from Cbv34 inhibited growth of E. coli to a comparable extent as the clinically established antibiotic gentamicin. Liquid-chromatography coupled mass spectrometry analyses revealed the presence of cystobactamids in OMVs, inhibitors of bacterial topoisomerase currently studied to treat different Gram-negative and Gram-positive pathogens. This work, may serve as an important basis for further evaluation of OMVs derived from myxobacteria as novel therapeutic delivery systems against bacterial infections. 


\section{Introduction}

Over the last decades bacterial resistance to antibiotics is rapidly rising, largely as a result of their wide availability, overuse and misuse [1]. As a result, antibiotic-resistant bacteria that are difficult to treat such as methicillin-resistant Staphylococcus aureus (S. aureus) [2] become highly common and are causing a serious global health problem [3]. In Europe alone up to 25,000 patients die each year as a result of those infections which is costing the European Union $€ 1.5$ billion annually [2]; and these numbers are seriously on the rise. One way of addressing the challenging question of how to deal with drug-resistant bacteria is still the discovery of novel antibiotic compounds [4]. However due to the risk of spontaneous resistance development, pharmaceutical companies investigate far less into the cost-intensive development process for new antibiotics than 30 years ago $[1,3]$. Another viable strategy to bypass bacterial resistance is to encapsulate known antibiotics into nanoparticulate drug delivery systems ("nanoantibiotics") [5, 6]. Nanoparticles are among the promising avenues to improve drug transport to the site of infection [7, 8]. Loading of antibiotics polymyxin $\mathrm{B}$ and ampicillin into liposomes was shown to significantly increase the antibiotic activity, even against difficult pathogens such as $P$. aeruginosa and S. aureus [9]. Moreover, encapsulation into nanoparticles can reduce adverse side-effects such as acute kidney injury induced by aminoglycosides $[10,11]$. However, the ability of certain nanoantibiotics to exclusively target pathogenic bacteria leaving commensal bacteria of the natural microflora unaffected is often suboptimal [9] and they may potentially induce immunogenicity due to their synthetic origin $[9,10]$, both problems manifest upon repeated administration which is necessary during long-term antibiotic therapy. Biogenic approaches, such as cell-derived vesicles [12], are found in nature or based on natural processes and they represent a promising alternative to artificial systems as they can potentially bypass immune activation and are inherently biocompatible $[13,14]$. Such avenues offer a unique opportunity to learn from their physiological role and tissue interaction paving the way to develop new bioinspired drug carriers [15].

Extracellular vesicles (EVs) are small phospholipid based nanoparticles decorated with membrane and surface proteins and they are thought to be involved in cell-to-cell transfer of information [16, 17]. EVs are currently explored for potential therapy of different applications ranging from cancer therapy [18], inflammation [19], gene delivery [20] and to fighting infections [21] because of their natural composition and inherent targeting properties [22]. Nevertheless, ongoing limitations of EVs include issues of upscale production in a biotechnologically controllable manner and post-processing regarding loading and modification for targeted tissue interaction [23] which may overall compromise their applicability in clinical trials. In this work, we investigate a non-toxic and biocompatible type of EVs, namely outer membrane vesicles (OMVs) isolated from non-pathogenic soil-bacteria called myxobacteria. Since myxobacteria are inexpensive to ferment, their OMVs may thus be biotechnologically easily accessible and on top of that we show that they are inherently loaded with a recently discovered class of antibiotics effective against Gram-negative bacteria. 
Outer membrane vesicles (OMVs) are spherical nanoparticles produced by Gram-negative bacteria $[24,25]$. They originate from budding of the bacterial outer membrane and have been shown to hold manifold functions, including communication among bacteria themselves [26], involvement in procurement of nutrients, biofilm formation [27], transfer of virulence factors [28] or immunomodulation of the host [29]. OMVs are studied in detail for vaccination applications [30] with candidates now tested in clinical studies. OMVs have also been engineered for cancer therapy applications [31] but not in detail for delivery of antimicrobial compounds. Interestingly, OMVs can naturally carry bacteriolytic secondary metabolites, using them as weapons during the competition for environmental niches [32]. There are examples of inherently bacteriolytic OMVs derived from pathogens such as Pseudomonas aeruginosa [33]. It has been shown that some OMVs derived from other strains, e.g. Enterobacter or Citrobacter are able to kill other bacteria by transporting peptidoglycan hydrolases into their prey [34]. Although an interesting property, it remains doubtful whether such potentially strong immunogenic particles may be used in humans. To bypass these biocompatibility issues, we employed myxobacteria as producers of OMVs [35]. Myxobacteria are a class of $\delta$-proteobacteria, which are predominantly found in soil. They are producers of versatile secondary metabolites, which offer new effective mechanisms of action and, among other effects, have antibacterial activity [36]. Most importantly, myxobacteria are non-pathogenic to humans but they show a predatory lifestyle and prey on other bacterial competitors [37]. Myxobacteria prey on Gramnegative and Gram-positive bacteria as nutrient source [38] and they are not able to synthesise three branched chain amino acids such as leucine, valine and isoleucine [39]. It was previously shown that Myxococcus xanthus produce hydrolase containing OMVs to kill competing bacteria [40]. Such unspecific enzyme induced antimicrobial effect may not be selective enough to kill prokaryotic cells while leaving human tissue unaffected.

Here, we thus aimed at identifying new candidates of myxobacterial OMVs that physiologically contain antibiotic compounds for a selective and efficient treatment of bacterial infection. We further investigated the natural properties of myxobacteria OMVs including their inherent antimicrobial potential against Gram-negative model bacteria E. coli and their compatibility with human cells. We characterised OMVs from two myxobacterial strains, namely Cystobacter velatus strain Cbv34 and the unclassified Sorangiineae species strain SBSr073 and show that they are biocompatible and stable at different storage conditions. OMVs possess an inherent antimicrobial effect against model pathogens which was comparable to the clinically used antibiotic gentamicin. Our results create an important basis for an advanced development of bacterial OMVs as alternative antimicrobial drug carriers.

\section{Materials and Methods}

\section{Microbial culture}


Strain SBSr073 of the Sorangiineae suborder was cultivated in 2SWT medium (Bacto tryptone $0.3 \%$, Soytone $0.1 \%$, Glucose $0.2 \%$, Soluble starch $0.2 \%$, Maltose monohydrate $0.1 \%$, Cellobiose $0.2 \%, \mathrm{CaCl}_{2} 2 \mathrm{H}_{2} \mathrm{O} 0.05 \%, \mathrm{MgSO}_{4} 7 \mathrm{H}_{2} \mathrm{O} 0.1 \%$, HEPES $10 \mathrm{mM}, \mathrm{pH} 7.0$ adjusted with $\mathrm{KOH}$ ). Cystobacter velatus (Cbv34), a member of the Cystobacterineae suborder, was cultivated in $\mathrm{M}$ medium (1.0\% soy peptone, $1.0 \%$ maltose, $0.2 \% \mathrm{CaCl}_{2}, 0.1 \% \mathrm{MgSO}_{4}, 50 \mathrm{mM} \mathrm{HEPES} \mathrm{pH} 7.2$ and 8 $\mathrm{mg} / \mathrm{L}$ Fe-EDTA) at $30{ }^{\circ} \mathrm{C}$ and maintained at $180 \mathrm{rpm}$. Escherichia coli (E. coli) DH5-alpha bacteria (DSM 6897) were incubated at $37^{\circ} \mathrm{C}$ and $180 \mathrm{rpm}$ in lysogeny broth medium. All cultures were split after reaching stationary phase (Figure S1). SBSr073 forms aggregates and therefore the measured optical density at $600 \mathrm{~nm}$ (OD600) was inconclusive. Hence, the culture was split after 8 days of incubation of a $1 \%(\mathrm{v} / \mathrm{v})$ inoculum. A growth curve of Cbv34 was established by measuring the OD600 twice a day with a cell density meter model 40 (Fischer Scientific, USA) with semi-micro cuvettes using medium as blank. Cbv34 bacterial culture was started at an OD600 of 0.1 and the stationary phase was reached after 4 days at an OD600 of 3.8. A cryogenic culture of all strains was established in $25 \%$ (v/v) glycerol.

\section{Isolation and purification of $O M V S$}

For optimal OMV isolation from conditioned media, myxobacteria needed to be cultured for at least four passages when they reached their stationary phase. Conditioned media from all strains were collected in $50 \mathrm{~mL}$ falcon tubes and their OMVs isolated using our previously established protocol [41]. In brief, they were centrifuged at $9500 \times \mathrm{g}$ for $10 \mathrm{~min}$ at $4{ }^{\circ} \mathrm{C}, 40 \mathrm{~mL}$ of the supernatant was then carefully transferred by pipetting into new falcon tubes and centrifuged at $9500 \mathrm{xg}$ for $15 \mathrm{~min}$ at $4{ }^{\circ} \mathrm{C}$. Afterwards, $30 \mathrm{~mL}$ of this supernatant was filled into ultracentrifugation tubes and pelleted at 100,000 $\mathrm{x} \mathrm{g}$ and $4{ }^{\circ} \mathrm{C}$ for 2 hours (rotor SW 32 Ti, Beckman Coulter). The supernatant was removed carefully and the pellet was re-suspended with $400 \mu \mathrm{L}$ filtered phosphate buffered saline (PBS, Gibco PBS tablets without calcium, magnesium and phenol red). To check if the isolation successfully removed living bacteria, $100 \mu \mathrm{L}$ of this pellet were spread on agar plates, containing all nutrients from each media plus $1.5 \%(\mathrm{w} / \mathrm{v})$ agar and incubated at $30{ }^{\circ} \mathrm{C}$ for 8 days.

For further purification, the pellet was applied on a size exclusion chromatography (SEC) column filled with sepharose CL-2B (GE Life Science, United Kingdom) to separate vesicles from proteins that may have as well been pelleted during ultracentrifugation. The pellet to gel ratio was approximately 1 in 100 parts. Fractions of 0.5 to $1 \mathrm{~mL}$ were collected into polypropylene (PP) tubes (Axygen) (Figure S2) and stored at $4{ }^{\circ} \mathrm{C}$ for up to one week before further characterisation.

\section{Characterisation of OMVS}

Size distribution and yield of OMVs were assessed using Nanoparticles Tracking Analysis (NTA LM-10, Malvern, United Kingdom). To ensure equivalent results, samples were diluted up to 1:1000 in order to have a concentration of 20 to 120 particles per frame. $100 \mu \mathrm{L}$ of sample were 
applied onto the chamber equipped with a green laser. A video was recorded with a camera level varying between 13 and 15 using NanoSight 3.1. Each sample was recorded three times for 30 seconds and calculated with a detection threshold of approximately 5 to ensure results are comparable amongst each other.

To determine the protein concentration of the fractions collected from SEC, a bicinchoninic assay kit (Sigma Aldrich) was used, according to manufacturer's specification. All samples were analysed in duplicates against an albumin standard with concentrations of $0.5,5,10,20$ and $30 \mu \mathrm{g} / \mathrm{mL}$. Polydispersity index (PDI) and zeta potential of OMVs was measured on a Malvern Zetasizer.

\section{Electron microscopy of OMVs}

For electron cryomicroscopy (cryo-EM), OMVs were purified as described above and dispersions with a concentration of $\sim 10^{11}$ particles $/ \mathrm{mL}$ were used for analysis. For sample preparation a $3 \mu \mathrm{L}$ droplet was placed onto a holey carbon film (type S147-4, Plano) before plotting for 2 sec using a Gatan cryoplunger model CP3 (Pleasanton) and plunging into liquid ethane at $\mathrm{T}=108 \mathrm{~K}$. The frozen samples were transferred under liquid nitrogen to a Gatan model 914 cryo-TEM sample holder and investigated by bright-field TEM imaging at T=100 K and 15 pA/ $\mathrm{cm}^{2}$ (JEM-2100 LaB6, Jeol).

\section{Biocompatibility of OMVS}

A ToxinSensor ${ }^{\mathrm{TM}}$ Chromogenic LAL Endotoxin assay kit (GenScript), which is an enzyme based chromogenic test, was used to determine the endotoxin concentration of OMVs. It is an alternative to the gel-clot and turbidimetric tests for lipopolysaccharide (LPS) quantification. According to the manufacturer's specification all samples were examined within either $24 \mathrm{~h}$ after isolation or stored at $-20{ }^{\circ} \mathrm{C}$ before analysis. After mixing the sample with a limulus amebocyte lysate, the proteolytic activity of factor $\mathrm{C}$ was activated by endotoxins. The protease then catalysed the cleavage of p-nitroaniline (pNA) of a synthetic peptide (Ac-Ile-Glu-Ala-Arg-pNA). After diazocoupling of pNA the absorbance was read at $545 \mathrm{~nm}$ using a polystyrene 96 well plate. All samples were measured in technical duplicates.

Biocompatibility of OMVs was studied by assessing viability and cytotoxicity two cell types, namely epithelial lung carcinoma cells (A549) and acute monocytic leukemia monocytes (THP-1) which were activated to macrophages. These cell lines were chosen to simulate interactions of OMVs with epithelial barriers and immune cells present at sites of infections. A549 cells were seeded into 96well plates at densities of 10,000 to 20,000 cells/well and left to grow for $48 \mathrm{~h}$. THP-1 cells were seeded into 96-well plates at densities of 100,000 cells/well, subsequently differentiated to adherent macrophages (dTHP-1) with $30 \mathrm{ng} / \mathrm{mL}$ of phorbol 12-myristate 13-acetate (PMA) and left to grow for $48 \mathrm{~h}$. Then, the old cell culture medium was replaced with fresh serum free and phenol red free RPMI 1640 medium (Thermo Fisher) and the cells were incubated with 50, 500, 5000 and 50000 purified OMVs/cell, and PBS as negative control and Triton X 1\% (w/v) as positive control for $24 \mathrm{~h} .100 \mu \mathrm{L}$ of 
cell-free supernatant were transferred to a fresh 96-well plate for subsequent lactate dehydrogenase assay (LDH assay, see below). To assess cell viability, cells were washed and mixed with $100 \mu \mathrm{L}$ fresh medium and $100 \mu \mathrm{L} \mathrm{10 \%} \mathrm{PrestoBlue} \mathrm{Cell} \mathrm{Viability} \mathrm{Reagent} \mathrm{(Thermo} \mathrm{Fisher)} \mathrm{in} \mathrm{medium.} \mathrm{Cells}$ were incubated at $37{ }^{\circ} \mathrm{C}$ for $10 \mathrm{~min}$ to $2 \mathrm{~h}$, bottom fluorescence was read (excitation $560 \mathrm{~nm}$ and emission $590 \mathrm{~nm}$ ) and viability calculated in comparison to PBS controls. For LDH detection in supernatants, a kit (Cytotoxicity Detection Kit, Merck) was used per supplier's instructions by incubating with the reaction mixture and an absorbance measurement at $490 \mathrm{~nm}$.

\section{Storage stability of OMVs}

Each OMV sample was stored in PBS and at $4{ }^{\circ} \mathrm{C},-20{ }^{\circ} \mathrm{C},-80{ }^{\circ} \mathrm{C}$ and freeze dried to evaluate their stability [42]. Aliquots of $100 \mu \mathrm{L}$ of each sample were kept in MaxyClear microtubes (Axygen) to avoid vesicles absorption to the plastic surface of the tubes. After determining particle concentration and size by NTA (correspond to $100 \%$ ), the samples were stored for 7 to 75 days. For freeze-drying (lyophilisation), samples were snap frozen with liquid nitrogen and then dried overnight for at least 16 h using a LypoCube (Christ) freeze dryer.

\section{Liposome controls}

Liposomes were prepared using a mixture of 1,2-dimyristoyl-sn-glycero-3-phosphorylcholine (DMPC) and dipalmitoyl phosphatidylcholine (DPPC) at a ratio of 2:3 (mol\%) and a concentration of $5 \mathrm{mM}$ in a final volume of $1 \mathrm{~mL}$. They were prepared using thin-film hydration as described previously [43]. In brief, lipids were suspended in filtered PBS at $42{ }^{\circ} \mathrm{C}$, and extruded 21 times through a $200 \mathrm{~nm}$ polycarbonate membrane (all material from Avanti Lipids).

\section{Uptake assessment and antibiotic activity of OMVS}

Liposomes and OMVs were labelled and their cellular uptake was assessed in E. coli DH5alpha model bacterium grown to an OD600 of 0.15. Liposomes and OMVs of SBSr073 and Cbv34 were incubated with $1 \mu \mathrm{L}$ DiI (Vybrant DiI Cell-labelling solution) for 30 minutes. Non-incorporated dye was removed by SEC. The fluorescence intensity of each fraction was measured and the two most concentrated OMV fractions were used for further evaluation. After incubating E. coli with OMVs and liposomes for $1 \mathrm{~h}, 8 \mathrm{~h}$ and $24 \mathrm{~h}$ the bacteria were labelled with $1.5 \mu \mathrm{L}$ SYTO 9 Green fluorescent nucleic acid stain and incubated at $37{ }^{\circ} \mathrm{C}$ for $10 \mathrm{~min}$. After centrifugation at $9500 \mathrm{x} \mathrm{g}$ for $5 \mathrm{~min}$, bacteria were fixed with $4 \%$ paraformaldehyde for $10-15 \mathrm{~min}$ at $37^{\circ} \mathrm{C}$. Before applying $10 \mu \mathrm{L}$ of sample on a coverslip with a drop of mounting medium all samples were washed with PBS. Images were taken using a Leica TCS SB8 confocal microscope with a $64 \mathrm{x}$ magnification lens. A laser with an excitation wavelength of $561 \mathrm{~nm}$ (digital gain: $82 \%$, pinhole: $111.5 \mu \mathrm{m}$, filter: $566-673 \mathrm{~nm}$, laser intensity: $2.0 \%$ ) was set up to visualise DiI labelled vesicles and liposomes. Another laser with a wavelength of $488 \mathrm{~nm}$ (digital gain: 11\%, pinhole: $111.5 \mu \mathrm{m}$, filter: $493-554 \mathrm{~nm}$, laser intensity: 2.0\%) 
was used to visualise SYTO 9 stained bacteria. All images were taken with the same set up, averaging and speed to allow sample comparison; and analysed using the Zen 2012 SP1 (black edition) software.

The antimicrobial effect of vesicles on E. coli DH5-alpha was analysed by incubating $100 \mu \mathrm{L}$ of bacteria suspension (OD600 of 0.1) with $100 \mu \mathrm{L}$ OMVs in a 96 PS well plate. Sterile PBS was used as a negative control and antibiotic gentamicin $(16 \mu \mathrm{g} / \mathrm{mL})$ was applied as positive control. To prevent evaporation, the outer wells of the microplate were filled with water. The plate was incubated at $37{ }^{\circ} \mathrm{C}$ in a Tecan infinite 200 Pro plate reader, measuring the absorbance at $600 \mathrm{~nm}$ every $15 \mathrm{~min}$ for at least $16 \mathrm{~h}$. OMVs were also diluted 1:5, 1:10, 1:50 or 1:100 with sterile PBS in order to calculate a dose response curve. Colony-forming units (CFU) were measured by incubating OMVs with E. coli. For this, E. coli DH5-alpha was cultivated in lysogeny broth at $37^{\circ} \mathrm{C}$ and $180 \mathrm{rpm}$ until log phase was reached. The bacterial culture was diluted to $10^{8} \mathrm{CFU} / \mathrm{ml}$ and incubated overnight with different concentrations of purified OMVs $\left(10^{10}, 10^{11}\right.$ and $10^{12}$ vesicles $\left./ \mathrm{mL}\right)$. Serial dilutions of the samples were prepared, inoculated on lysogeny broth agar plates and incubated overnight at $37^{\circ} \mathrm{C}$. Afterwards $\mathrm{CFUs} / \mathrm{mL}$ were counted and quantified.

\section{Liquid-chromatography coupled mass spectrometry}

To assess the active principle within myxobacterial OMVs, they were analysed by liquidchromatography coupled mass spectrometry (LC-MS). First, $1 \mathrm{~mL}$ of purified OMV sample was mixed with $1 \mathrm{~mL}$ of methanol to achieve complete solubilisation of EVs. After solvent evaporation the residue was taken up in $150 \mu \mathrm{L}$ of methanol and centrifuged at $21500 \times \mathrm{g}$ for $5 \mathrm{~min}$ to remove debris and insoluble salts. $1 \mathrm{~mL}$ of this sample was subsequently analysed by UHPLS-HRMS on a Dionex Ultimate 3000 RSLC system using a Waters BEH C18 column $(50 \times 2.1 \mathrm{~mm}, 1.7 \mu \mathrm{m})$ connected to a Waters VanGuard BEH C18 $1.7 \mu \mathrm{m}$ guard column. Separation of $1 \mu 1$ sample was achieved by a linear gradient from (A) $\mathrm{H}_{2} \mathrm{O}+0.1 \%$ FA to (B) ACN $+0.1 \%$ FA at a flow rate of $600 \mu \mathrm{L} / \mathrm{min}$ and $45{ }^{\circ} \mathrm{C}$ column temperature. Gradient conditions were as follows: $0-0.5 \mathrm{~min}, 5 \% \mathrm{~B} ; 0.5-18.5 \mathrm{~min}, 5-95 \%$ B; 18.5 - $20.5 \min , 95 \%$ B; 20.5 - 21 min, 95 - 5\% B; 21-22.5 min, 5\% B. UV spectra were recorded by a diode-array detector in the range from 200 to $600 \mathrm{~nm}$. The LC flow was split to $75 \mu \mathrm{L} / \mathrm{min}$ before entering the Bruker Daltonics maXis 4G hr-qToF mass spectrometer using the Apollo II ESI source. Mass spectra were acquired in centroid mode ranging from $150-2500 \mathrm{~m} / \mathrm{z}$ at a $2 \mathrm{~Hz}$ full scan rate and data were annotated using the in house myxobacterial metabolome MXbase Database, established at the Helmholtz Institute for Pharmaceutical Research Saarland (HIPS), by automated comparison of retention time, exact mass and isotope pattern accuracy using Bruker Daltonics Target analysis 1.3. A detailed description of spectra annotation can be found in the supplementary information.

\section{Statistical analysis}

All data are displayed as mean \pm standard deviation (SD), indicating the number of $n$ independent experiment in each figure. All measurements were at least made in independent 
triplicates. Results were analysed statistically with Sigma Plot using One-way ANOVA followed by Tukey post-hoc test to compare the mean values between individual groups. Significant p-values were illustrated as $*$ for $p<0.05$ and $* * p<0.005$.

\section{Results and Discussion}

\section{OMVs are efficiently isolated from bacterial culture and they show promising storage stability}

In this work, we compared two strains of myxobacteria from representative suborders as source for OMVs, namely SBSr073 (Sorangiineae suborder) and Cbv34 (Cystobacterineae suborder). According to our growth curves strain Cbv34 showed a doubling time of $\mathrm{tD}_{\mathrm{Cbv3} 3}=4.7 \mathrm{~h} \pm 1.0$, reaching stationary phase after $50 \mathrm{~h}$ (Figure S1a). To obtain the maximum amount of OMVs while avoiding artefacts of dead cells or presence of protein aggregates, we decided to use conditioned medium after $80 \mathrm{~h}$ (stationary phase) for their isolation (Figure S1b). It is important to mention, that both strains require at least four full passages after starting the culture from cryogenic stocks to achieve optimal bacterial growth (Figure S1c). Strain SBSr073 formed aggregates when in liquid medium, which made OD600 measurements inconclusive (Figure S1d). When dispersing clumps with glass beads and under vortexing, aggregates would form again within 2 days of culture. Thus samples of conditioned medium were generally taken after 8 days of growth and with bacterial morphology not altered. Bright field microscopy of both bacterial strains revealed typical rod shape of myxobacteria and similar culture conditions were used throughout the entire study to ensure reproducible OMV properties. For strain Cbv34, we obtained best OMV results when the culture medium reached a viscous constitution. We were able to keep these myxobacteria in constant culture for more than 3 months without loss of phenotype or major alterations of morphology as observed by light microscopy.

OMVs were subsequently isolated from conditioned culture medium using differential ultracentrifugation [43]. Bacteria were removed by centrifuging the culture at $9500 \mathrm{x} g$ for 10 minutes and $15 \mathrm{~min}$. After the ultracentrifugation at $100,000 \times \mathrm{g}, 100 \mu \mathrm{L}$ of in PBS re-suspended pellet were plated on agar plates and incubated for 8 days to verify that all bacteria had been removed during centrifugation and the final pellet contained only OMVs (Figure S1e). Re-suspended OMV pellets were purified by SEC to separate protein aggregates from vesicles. This technique is effective for separating molecules and particles according to their size. The successful purification of the OMVs from soluble proteins is shown in Figure S2, suggesting that OMVs mainly eluted at 6-8 $\mathrm{mL}$ for SBSr073 and 7-9 $\mathrm{mL}$ for Cbv34 with free protein aggregates eluting at fractions 15 and later. We subsequently pooled the highest concentrated fractions to assess the OMVs using cryo-EM (Figure 1a). This method was mainly applied to study morphology and shape of vesicles derived from both bacterial strains [44]. The lipid-bilayer is clearly visible which indicates that OMVs were not all destroyed during isolation and purification. These images also show that the combination of 
ultracentrifugation with SEC to purify OMVs was reproducible without inducing artefacts from membrane fusion or disruption. In few images we observed multi-lamellar vesicles which may be a type of the recently described outer-inner membrane vesicles [45]. These particles were reported to occur in only up to $1.2 \%$ of OMV preparations from selected strains, which is consistent with our observations in cryo-EM images. To verify these findings, the particle concentration and size of all collected fractions was analysed by NTA (Figure 1b). In all subsequent experiments, OMV quantification was only based on NTA measurements. The most abundant fractions contained concentrations of $10^{10}-10^{11}$ particles $/ \mathrm{mL}$ which is $10-100$ fold more than vesicle concentrations reported for mammalian cells [43]. Indeed, low EV amount is one of the major challenges when developing these biogenic carriers for drug therapy [23]. However, microbial culture is already an established biotechnological process with the possibility to upscale which is a big asset to produce these nanodelivery systems. The average hydrodynamic radius of OMVs measured by NTA was $145 \mathrm{~nm}$ for Cbv34, and $194 \mathrm{~nm}$ for SBSr073 OMVs. When further assessing the physio-chemical properties of purified OMVs, we observed a relatively small PDI of 0.14 and 0.22 for SBSr073 and Cbv34 (Table S1), respectively, which may suggest that with these sizes OMVs can be filtered to sterility [46]. Despite OMVs are derived from cells, their size distribution is rather narrow and it suggests that the majority of the particles have a homogenous distribution.

a)

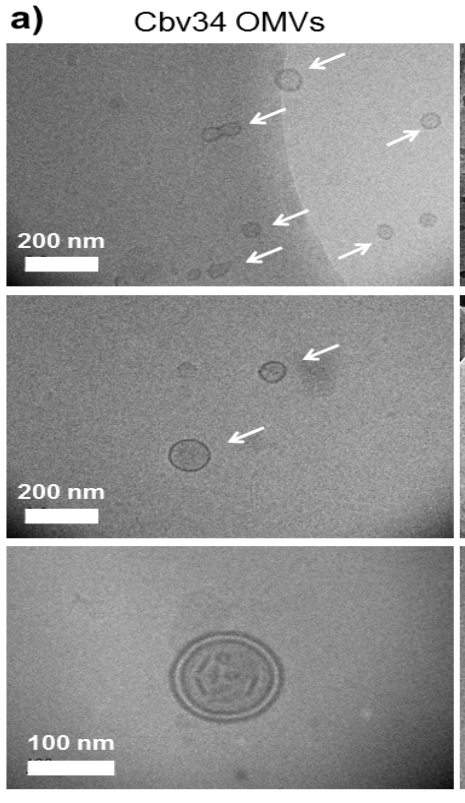

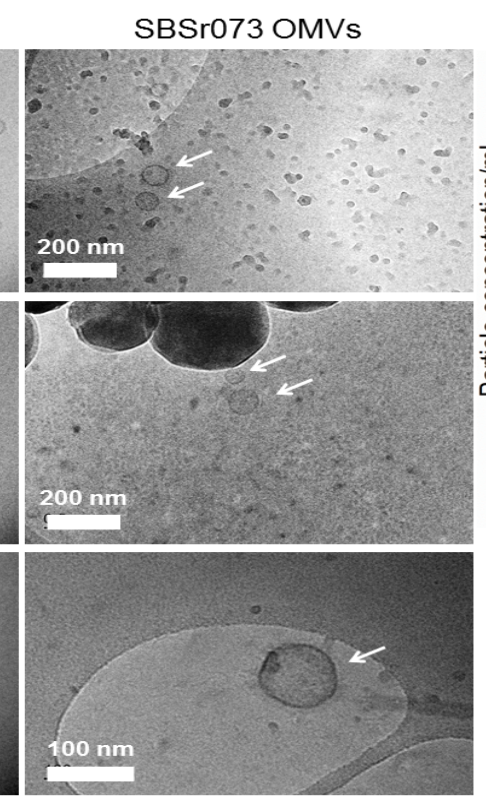

b)
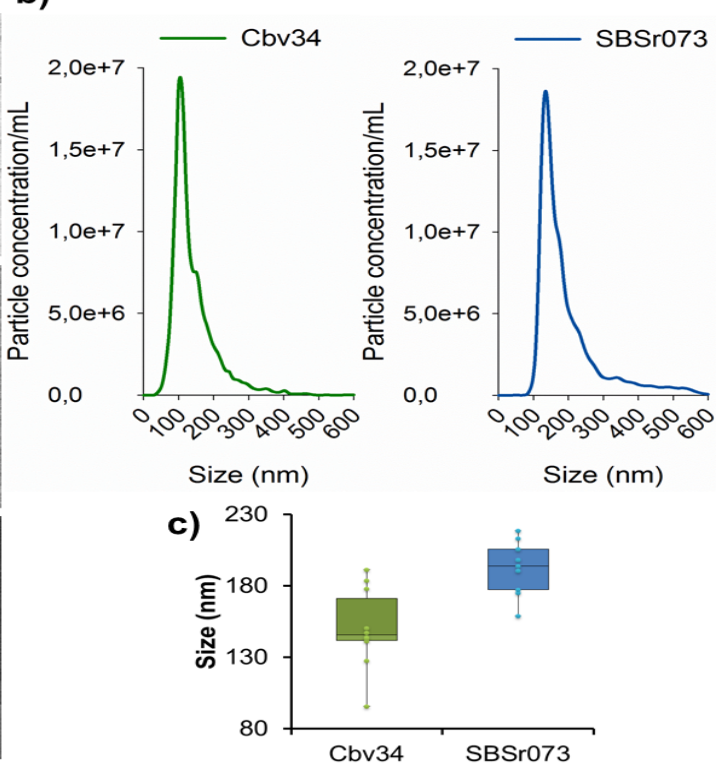

Figure 1. Electron cryomicroscopy characterisation and size distribution of myxobacterial OMVs. a) OMVs were analysed by cryo-EM at different magnifications and are marked with arrows. Bright areas in the images indicate regions of lower transmission, small and big black spots in the SBSr073 samples are ice crystals as identified by their shape. b) Averaged spectra of size distribution of OMVs from Cbv34 and SBSr073 measured by nanoparticle tracking analysis after size exclusion chromatography purification and c) corresponding boxplot of average OMV sizes, Mean $\pm \mathrm{SD}, n=10$. 
Due to their cellular origin, the zeta potential of OMVs was slightly negative which is often associated with low stability and tendency to aggregate. We thus investigated the stability of these vesicles by storing samples at $4{ }^{\circ} \mathrm{C},-20^{\circ} \mathrm{C},-80{ }^{\circ} \mathrm{C}$ and upon lyophilisation (freeze-drying) (Figure 2). After 7 and 75 days, size and particle concentration was measured and compared to day zero (set to $100 \%)$. A reduction in particle concentration was seen at all conditions after 7 days but was less pronounced for Cbv34 OMVs with a decrease to $70 \%$ when freeze-dried and $40 \%$ when stored at -80 ${ }^{\circ} \mathrm{C}$ (Figure 2a). Such loss may be due to unspecific agglomeration or disintegration of vesicles. After 75 days only $14 \%$ of OMVs were recovered when stored at $-20{ }^{\circ} \mathrm{C}$ but $40 \%$ remained when samples were lyophilized. SBSr073 OMVs were most stable during lyophilisation, even after 75 days (Figure 2c). Interestingly, a major size drift was observed when storing these OMVs at $4{ }^{\circ} \mathrm{C}$ (Figure 2d). Until now, there are very little reports on a standardized and preferred method for storing OMVs and EVs yet although it is essential for advanced studies [42, 47] and storage of vesicles at $-80{ }^{\circ} \mathrm{C}$ is recommended [48]. Our results indicate that freeze-drying is a valid alternative for storing OMVs as it was also shown in literature [42, 49]. Based on our stability data we decided to use OMVs within 3 days after purification. In all subsequent evaluations, OMVs and liposomes of $148 \mathrm{~nm}$ size were used at similar concentrations for appropriate comparison (Figure S3a).

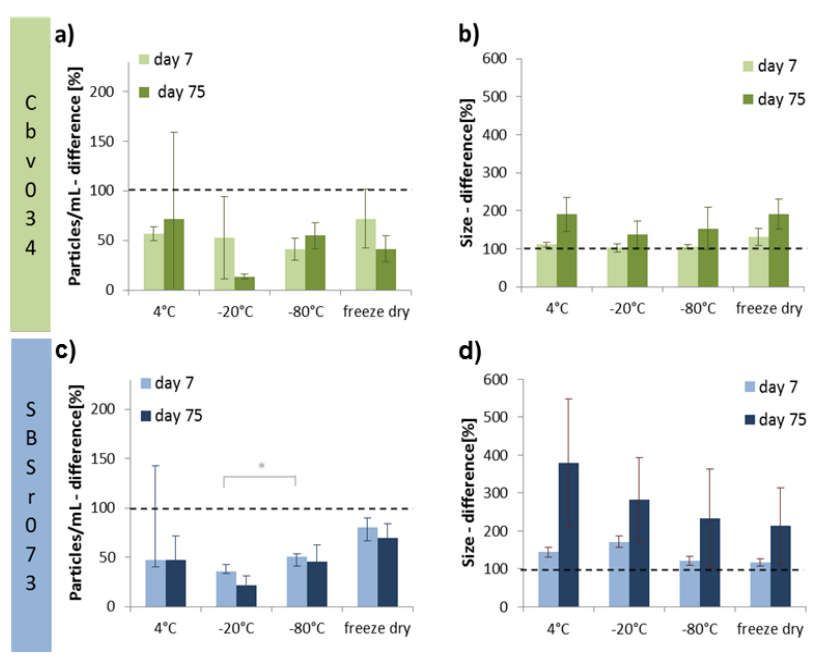

Figure 2. Stability of myxobacterial OMVs upon different storage conditions. OMVs from Cbv34 and SBSr073 were isolated, purified, and stored for 7 and 75 days in PBS and under different conditions $\left(4{ }^{\circ} \mathrm{C},-20{ }^{\circ} \mathrm{C},-80{ }^{\circ} \mathrm{C}\right.$, and after freeze-drying and at RT). a) Particle concentration of Cbv34 OMVs and b) evolution in size of Cbv34 OMVs, c) Particle concentration of SBSr073 OMVs, 
d) evolution in size of SBSr073 OMVs. Mean $\pm \mathrm{SD}, n=3, * p<0.05$ (ANOVA followed by Tukey post-hoc test).

\section{OMVs show very good biocompatibility and only little endotoxin activity}

Biocompatibility of myxobacterial OMVs was evaluated using epithelial A549 cells and differentiated dTHP-1 macrophages to assess cell viability and cytotoxicity (Figure 3). A549 cells were used as normal epithelial control cells while dTHP-1 cells were stimulated with concentrations of PMA (30 $\mathrm{ng} / \mathrm{mL})$ to stimulate differentiation to macrophages and mimic inflammatory processes that are often associated with bacterial infections [50]. When incubating OMVs with A549 and dTHP-1 cells at different vesicle-to-cell ratios, no impact on general cell viability was observed for any of the cells compared to PBS controls (Figure 3a and b). We further evaluated whether any underlying cytotoxicity was present by applying a lactate-dehydrogenase test which measures cellular toxicity and cytolysis. Interestingly, even at very high concentrations of 50,000 OMVs/cell no cytotoxic effects were observed which indicated no immanent toxicity in our in vitro cell models (Figure 3c and d). Differentiated dTHP-1 cells are macrophage cells with a high phagocytosis rate and are potentially sensitive towards external stimuli but in our hands we did not see signs of distress or alterations in cell morphology when dTHP-1 cells were incubated at high OMV concentrations (Figure 3e) and in comparison to positive controls using cytotoxic Triton X. In dTHP-1 cells we see a small increase in cell viability upon addition of very large quantities of OMVs which may be induced by a nutrient bolus of lipids due to the high OMV concentration. No toxic effects were observed for control liposomes used at the same concentrations as OMVs (Figure S3b and c).

To analyse the potential of OMVs to induce immune reactions during application in a therapeutic setting, a chromogenic limulus amoebocyte lysate endotoxin assay was performed. Such endotoxin assay allows an estimation on the biocompatibility of a material as it gives information if samples contain immuno-stimulatory lipopolysaccharides. As OMVs could not be prepared under sterile conditions, we used the PBS wash from the SEC column as negative control. We observed that the endotoxin concentration of OMVs was not increased compared to the PBS negative control (Figure 3f). As another control, the endotoxin activity of strain Cbv34 and E. coli bacteria were measured when reaching the same OD600 of 3.5. Interestingly, although the bacterial density was comparable, E. coli showed a higher concentration of endotoxins (1.60 EU/mL), while strain Cbv34 exhibited low levels of endotoxins comparable to their OMVs $(0.75 \mathrm{EU} / \mathrm{mL})$ and to PBS controls. Our results suggest a lower endotoxin activity of myxobacterial OMVs compared to other Gram-negative microbial materials in general. It has been shown that some myxobacteria have a lack of LPS as a component of their outer membrane [51]. Ruiz et al. found an altered immune response of myxospores in sheep compared to other Gram-negative spores [52], which may be due to a partial modification of polysaccharides [53]. Our results suggest inherent biocompatibility of bacterial OMVs from myxobacteria, which may aid for their applicability in therapeutic settings. 

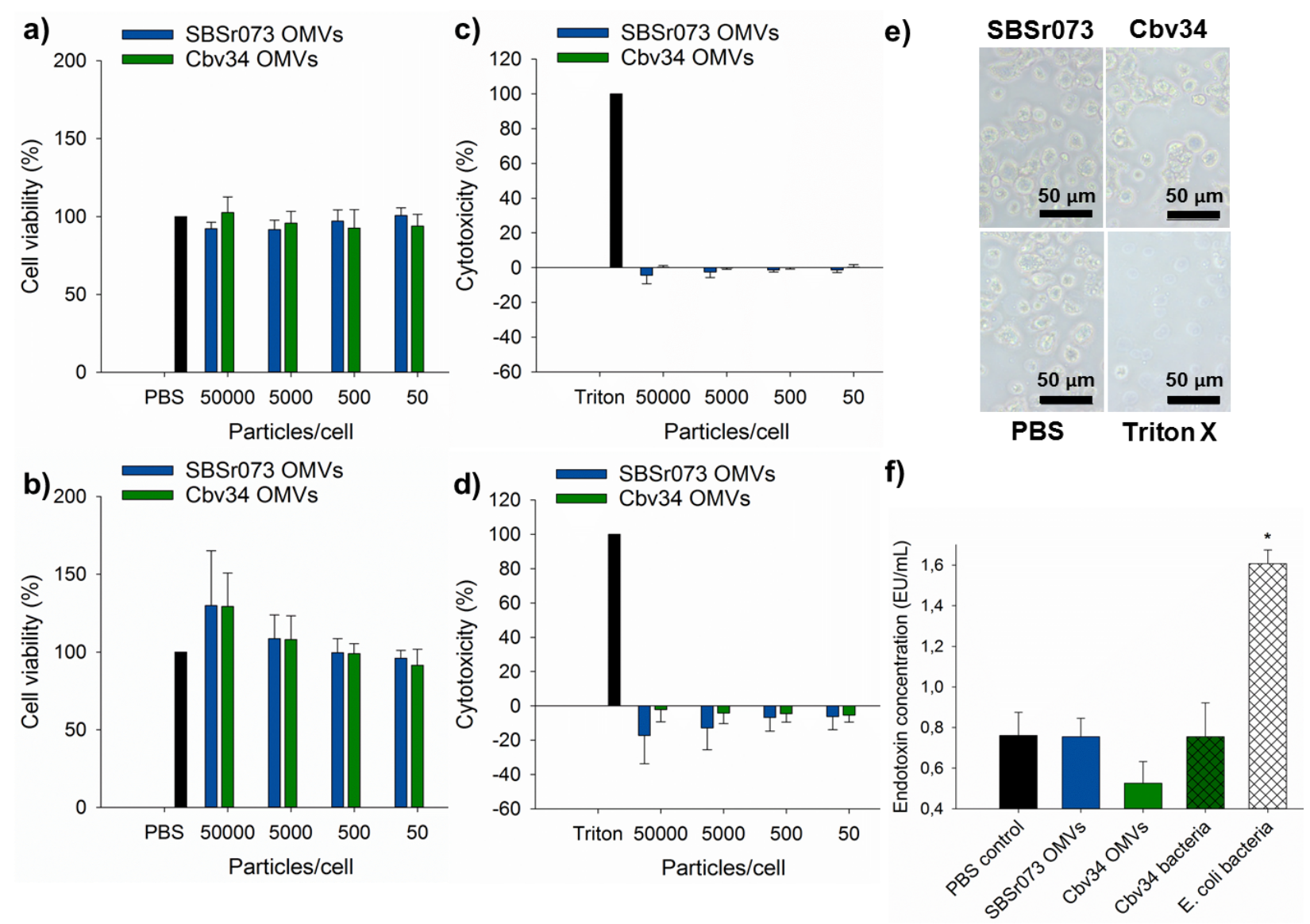

Figure 3. Biocompatibility and endotoxin assessment of myxobacterial OMVs. Cell viability of Cbv34 and SBSr073 OMVs when incubated for $24 \mathrm{~h}$ with a) A549 epithelial cells and b) dTHP-1 macrophage cells, and lactate-dehydrogenase cytotoxicity assay of OMVs incubated for $24 \mathrm{~h}$ with c) A549 and d) dTHP-1 cells. Mean \pm SD, $n=4-6$. e) Representative light microscopy images of dTHP1 cells incubated for $24 \mathrm{~h}$ with Cbv34 OMVs, PBS (negative control) or Triton X (1\%, positive control). f) Endotoxin activity of OMVs compared to control PBS collected from the SEC column under similar conditions. Cbv34 bacteria showed a lower concentration of endotoxins compared to $E$. coli when culturing samples with similar cell densities. Mean $\pm \mathrm{SD}, n=3,{ }^{*} p<0.05$ (ANOVA followed by Tukey post-hoc test)

The co-localisation of OMVs with model bacteria is comparable to standard liposomes

E. coli DH5-alpha were incubated with DiI labelled OMVs or liposomes for 1, 8, and $24 \mathrm{~h}$ in order to visualize interaction of OMVs with target model bacteria. The dyes were excited with two different lasers, for DiI at $561 \mathrm{~nm}$ and for detection of SYTO 9 labelled bacteria at $488 \mathrm{~nm}$. SYTO 9 was used for visualisation of all live and dead bacteria during microscopy. After $1 \mathrm{~h}$ (Figure S4) and 8 h of incubation with E. coli, very little to no co-localisation was detected for both types of OMVs and for liposomes. As seen in Figure 4 after 24 h incubation, we observed co-localisation of SYTO 9 labelled bacteria with DiI labelled OMVs (zoom in Figure 4b and arrows in Figure S4). Control 
samples incubating E. coli with DiI dye alone and in the absence of OMVs did not show co-localised fluorescence (Figure S5b). After 24 h of incubation with Dil labelled liposomes, we qualitatively observed less co-localisation. Liposomes may have accumulated in the extracellular matrix of the bacteria as indicated by a diffuse bright halo around the E. coli. For all experiments, comparable labelling efficiency of OMVs versus liposomes was employed (Figure S5a). We further studied zstack images of $E$. coli incubated for $20 \mathrm{~h}$ with Cbv34 OMVs (final concentration $10^{12} \mathrm{OMVs} / \mathrm{mL}$ ) which were washed before imaging (Figure S6). For some bacteria we observed co-localisation (indicated by arrows) but we also saw unspecific accumulation of OMVs in bacterial proximity. Overall, our results suggest that OMVs are co-localising with $E$. coli similarly to synthetic liposomes. There are three possible scenarios for OMVs to interact with cells, whether they belong to their own or competing other species: i) releasing cargo nearby cells, ii) physical fusion with the target outer membrane, or iii) by interaction with mammalian cell membranes via receptors. For OMV uptake into mammalian cells, different mechanisms ranging from direct fusion to endocytic uptake are currently discussed [54]. Evans et al. observed an increased fusion effect of OMVs when Glyceraldehyde 3phosphate dehydrogenase (GDPH) was added to E. coli [40]. The GDPH is an enzyme involved in eukaryotic membrane fusion, which may indicate that OMVs are eventually taken up through direct membrane fusion. We qualitatively observed a comparable co-localisation of natural vs. synthetic lipid carriers (i.e., OMVs vs. liposomes) in E. coli which may relate to the fluidity of the nanoparticle membrane in bacterial uptake as shown previously [55]. For other OMVs fusion with target bacteria was proposed [35], but upcoming assessments will need to indicate whether OMVs from Cbv34 and SBSr073 also follow this mechanism. Our findings nevertheless give a first insight into how interaction of OMVs compares to synthetic carriers which may serve as a point of reference to the creation of semi-synthetic OMV-mimetics with enhanced bacterial interaction. 

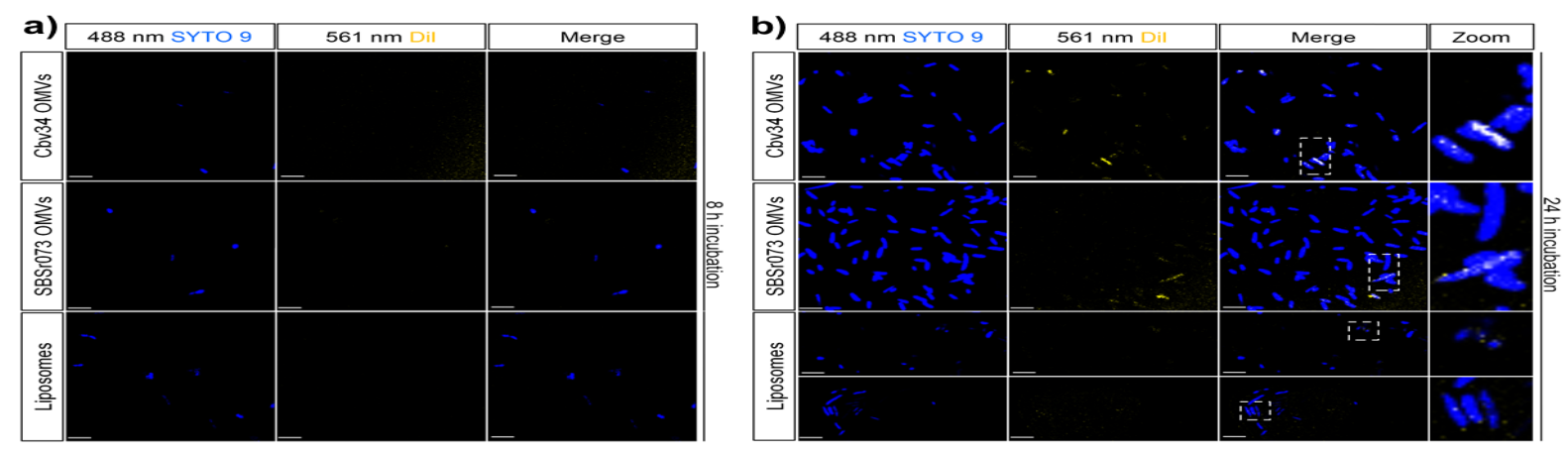

Figure 4. Representative confocal fluorescence images of $\boldsymbol{E}$. coli incubated with OMVs. $E$. coli DH5-alpha incubated with fluorescently (DiI)-labelled Cbv34 OMVs $\left(10^{11} / \mathrm{mL}\right), \operatorname{SBSr} 073\left(10^{10} / \mathrm{mL}\right)$ OMVs, and Liposomes $\left(10^{11} / \mathrm{mL}\right)$ for a) $8 \mathrm{~h}$ and b) $24 \mathrm{~h}$. Images were taken using the same laser settings at $561 \mathrm{~nm}$ and $488 \mathrm{~nm}$. Scale bars represent $5 \mu \mathrm{m}$. Zoomed-in images displayed show colocalisation of fluorescently labelled OMVs with magnified bacteria. Measurement settings and image analysis is similar for all images; false colouring was set to blue and yellow to better visualise colocalisation in the merged images.

OMVs are intrinsically loaded with antimicrobial drugs and show a growth inhibition using model bacteria

Following the promising results during uptake experiments in E. coli model bacteria, we investigated the antibacterial effect of OMVs. To do so, they were incubated with E.coli in a 96 well plate, screening the OD600 every 15 minutes. This simple real-time detection method showed that OMVs from Cbv34 had a strong inhibitory effect on E.coli growth when incubated at concentrations of $10^{12}$ vesicles $/ \mathrm{mL}$ (Figure 5a). As control, concentrations of $10^{12} \mathrm{OMVs} / \mathrm{mL}$ did not influence our OD600-based measurements in absence of bacteria. The OMV-induced inhibitory effect was comparable to a standard aminoglycoside antibiotic, gentamicin, at concentrations of $16 \mu \mathrm{g} / \mathrm{mL}$. To elucidate whether this inhibitory effect of OMVs was bacteriostatic or bactericidal we performed counting of CFUs after incubation with E. coli (Figure 5b). It was shown that Cbv34 OMVs completely inhibited bacterial growth when incubated at concentrations of $10^{12}$ vesicles $/ \mathrm{mL}$. Indeed, CFU counting confirmed our previously seen growth inhibition and the OMVs' effect was proven to be bacteriolytic because very small amounts of living colonies were observed upon plating. We calculated that $16 \mu \mathrm{g} / \mathrm{mL}$ gentamicin correspond to approximately $4 \times 10^{15}$ drug molecules to inhibit bacterial growth, while $2 \times 10^{11}$ OMVs induced a comparable effect. To further investigate this effect, we incubated E. coli with varying concentrations of OMVs which revealed a typical sigmoidal doseresponse curve (Figure 5c). In this OD600-based assay, OMV concentrations between $10^{11}$ and $10^{12}$ 
vesicles/mL were necessary to obtain the growth inhibition effect, which also matched our CFU data. Concentrations of $10^{11}$ to $10^{12}$ vesicles $/ \mathrm{mL}$ corresponded in our assay to an antimicrobial activity range of 140-2500 OMVs/CFU. We did not observe any impact on E. coli growth when incubating bacteria with comparable concentrations of control liposomes (Figure S3c). When further studying the OMV producers, we observed that Cbv34 bacteria were able to predate and lyse E. coli within $48 \mathrm{~h}$ of cultivation on agar (Figure S7), while SBSr073 bacteria were slowly swarming and showed weak predation. In consistency with these results, we only observed a small influence of SBSr073 OMVs on the growth rate of E. coli DH5-alpha. As seen in Figure 5a, SBSr073 OMVs appeared to induce a small bacteriostatic effect until 4-6 h of incubation with model bacteria which was not maintained during the entire incubation period of $16 \mathrm{~h}$. Nevertheless, given their biocompatibility profile, SBSr073 OMVs may in the future be loaded with common antibiotics to assess their delivery potential in an infection setting.

Myxobacteria are promising producers of various antibacterial compounds, as it was shown in literature [36]. We thus investigated the Cbv34 OMVs' active principle. In doing so, OMV samples were extracted using methanol as solvent and analysed by LC-MS. We identified a cystobactamid in the vesicle samples derived from Cbv34, eluting at a retention time of approximately 9 min and with an extracted ion chromatogram at $920.309 \pm 0.02 \mathrm{Da}$ (Figure S8). An scheduled precursor list based targeted $\mathrm{MS}^{2}$ experiment was applied to this main chromatographic peak in order to rule out massspectrometric artefacts and to confirm our finding. When comparing the OMV peak with a cystobactamid 919-1 standard we observed very good agreement in $\mathrm{MS}^{2}$ spectral fingerprint and displaying the subsequent losses of the derivatised p-aminobenzoic acid moieties from the cystobactamid backbone (Figure S9) which confirmed presence of the compound within Cbv34 OMVs. Unfortunately, it was not possible to quantify the amount of cystobactamid within acceptable error margins because of the limit of quantification and potential ion suppression effects induced by the OMV background signal. We further aimed at better analysing the antimicrobial effect of OMVs by determining the minimal inhibitory concentration of free cystobactamid $919-1$ to be $32 \mu \mathrm{g} / \mathrm{mL}$ using E. coli DH5-alpha model bacteria while Cbv34 OMVs showed a minimal inhibitory concentration of $10^{12}$ particles $/ \mathrm{mL}$. We also performed CFU counting of various cystobactamid and OMV concentrations (Figure S10). Mass spectrometry control experiments additionally revealed that cystobactamid is not contained in SBSr073 OMVs, pointing towards a role as active principle of Cbv34 OMVs. Cystobactamids are an important new class of antimicrobials which inhibit the bacterial type IIa topoisomerases and are effective against E.coli as well as several problem pathogens $[56,57]$. Thus intrinsically loaded biocompatible vesicles, as we showed here, alleviates drug carrier development in many ways: method validation for drug encapsulation is not needed, therefore the risk of modulating the vesicle membrane and its properties during post-processing is low. These naturallyequipped OMVs from strain Cbv34 may be an important step towards using EV-based therapies in the near future. 

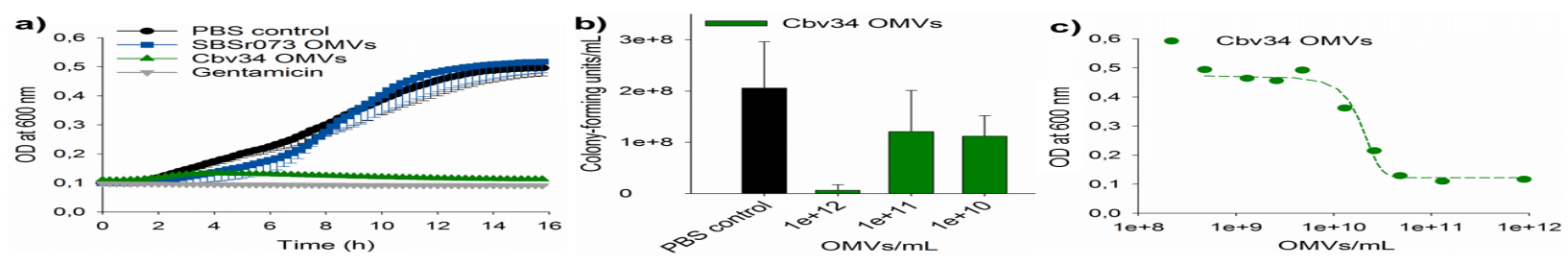

Figure 5. Inherent antibiotic effect of OMVs when incubated with $\boldsymbol{E}$. coli. a) Incubation of Cbv34 OMVs (concentration $10^{11} / \mathrm{mL}$ ) and SBSr073 OMVs (concentration $10^{10} / \mathrm{mL}$ ) with E. coli and in comparison to free gentamicin $(16 \mu \mathrm{g} / \mathrm{mL})$. Mean $\pm \mathrm{SD}, n=3$. b) Counting of colony-forming units of E. coli DH5-alpha incubated with different concentrations of Cbv34 OMVs. Mean $\pm \mathrm{SD}, n=3$. c) Dose response curve of Cbv34 OMVs by incubating increasing concentrations of OMVs with E. coli.

\section{Conclusions}

In this work, we present a new type of OMVs derived from myxobacteria that shows intrinsic antibiotic activity. These OMVs exhibit promising properties regarding size distribution and stability upon storage. Bacteria as sources for EVs are ideal as their high-yield cultivation on industrial scale is widely practiced which aides in the clinical translation of the current approach. Uptake studies indicated that OMVs are interacting with Gram-negative bacterial strains in a similarly manner than liposomes but further evaluations of these processes are required. Furthermore, advanced biocompatibility studies, such as an incubation of OMVs in complex in vitro models, and additional investigations regarding immunogenicity on other human cell lines or in small animal models are necessary. Regarding the OMV activity profile, it would be important to study other model bacteria or bacterial biofilms, which are an important barrier to successful antibiotic therapy at the moment [58]. Likewise, bacterial loading of cystobactamids into OMVs may be controllable through varying culture conditions. Indeed, lower potency of Cbv34 OMVs was observed when bacteria were used at lower passage numbers after inoculation from cryogenic stock indicating that culture periods may have an influence on antimicrobial activity (Figure S11).

The ability of these OMVs to target infected tissue would need to be studied using suitable in vivo models [6]. As their antimicrobial cargo compounds are naturally packed into OMVs, they are potentially protected from destruction by degrading enzymes which may reduce probability of new resistances [5]. OMVs may be bioengineered to possess small moieties enabling optimised targeting to pathogens while concurrently reducing accumulation in healthy mammalian cells as it was shown for other EVs [59]. These OMVs finally present a water-soluble version of poorly water-soluble cystobactamid which is relevant when developing this promising drug for other application routes, 
such as oral or lung delivery [60]. Ultimately, our findings provide an important step towards further developing OMVs from myxobacteria as promising antimicrobial drug carriers.

\section{Acknowledgements}

This work was supported by the NanoMatFutur Junior Research programme from the Federal Ministry of Education and Research, Germany (grant number 13XP5029A, BEVA). We thank Jennifer Herrmann for providing cystobactamid 919-1 standards.

\section{Author contributions}

E.S. conducted all experiments on OMVs isolation and characterisation, prepared figures and analysed experiments; A.G. assessed antimicrobial activity of OMVs together with E.S.; R.G. set-up the myxobacterial cultures and assisted in their maintenance; F.P. executed LC-MS analyses; M.K. collected electron cryomicroscopy images; R.M. provided myxobacterial strains and helped with the study design; K.F. executed biocompatibility analyses and supervised the work. G.F. conceived the study, supervised the project and wrote the main manuscript text together with E.S. All authors analysed data and reviewed the manuscript.

\section{Additional information}

The authors declare no competing financial interests. 


\section{References}

[1] H.R. Meredith, J.K. Srimani, A.J. Lee, A.J. Lopatkin, L. You, Collective antibiotic tolerance: mechanisms, dynamics and intervention, Nat Chem Biol, 11 (2015) 182-188.

[2] J.M.A. Blair, M.A. Webber, A.J. Baylay, D.O. Ogbolu, L.J.V. Piddock, Molecular mechanisms of antibiotic resistance, Nat Rev Micro, 13 (2015) 42-51.

[3] M. Perros, A sustainable model for antibiotics, Science, 347 (2015) 1062-1064.

[4] R. Sommer, S. Wagner, K. Rox, A. Varrot, D. Hauck, E.-C. Wamhoff, J. Schreiber, T. Ryckmans, T. Brunner, C. Rademacher, R.W. Hartmann, M. Brönstrup, A. Imberty, A. Titz, Glycomimetic, Orally Bioavailable LecB Inhibitors Block Biofilm Formation of Pseudomonas aeruginosa, J. Am. Chem. Soc., 140 (2018) 2537-2545.

[5] H. Zazo, C.I. Colino, J.M. Lanao, Current applications of nanoparticles in infectious diseases, J. Control. Release, 224 (2016) 86-102.

[6] R.S. Santos, C. Figueiredo, N.F. Azevedo, K. Braeckmans, S.C. De Smedt, Nanomaterials and molecular transporters to overcome the bacterial envelope barrier: Towards advanced delivery of antibiotics, Adv. Drug Deliv. Rev., (2017).

[7] P. Meers, M. Neville, V. Malinin, A.W. Scotto, G. Sardaryan, R. Kurumunda, C. Mackinson, G. James, S. Fisher, W.R. Perkins, Biofilm penetration, triggered release and in vivo activity of inhaled liposomal amikacin in chronic Pseudomonas aeruginosa lung infections, J. Antimicrob. Chemother., 61 (2008) 859-868.

[8] C.-M. Huang, C.-H. Chen, D. Pornpattananangkul, L. Zhang, M. Chan, M.-F. Hsieh, L. Zhang, Eradication of drug resistant Staphylococcus aureus by liposomal oleic acids, Biomaterials, 32 (2011) 214-221.

[9] A.J. Huh, Y.J. Kwon, "Nanoantibiotics": A new paradigm for treating infectious diseases using nanomaterials in the antibiotics resistant era, J. Control. Release, 156 (2011) 128-145.

[10] R.Y. Pelgrift, A.J. Friedman, Nanotechnology as a therapeutic tool to combat microbial resistance, Adv. Drug Deliv. Rev., 65 (2013) 1803-1815.

[11] R. Schiffelers, G. Storm, I. Bakker-Woudenberg, Liposome-encapsulated aminoglycosides in preclinical and clinical studies, J. Antimicrob. Chemother., 48 (2001) 333-344.

[12] P. García-Manrique, M. Matos, G. Gutiérrez, C. Pazos, M.C. Blanco-López, Therapeutic biomaterials based on extracellular vesicles: classification of bio-engineering and mimetic preparation routes, J Extracell Vesicles, 7 (2018) 1422676.

[13] A. Parodi, R. Molinaro, M. Sushnitha, M. Evangelopoulos, J.O. Martinez, N. Arrighetti, C. Corbo, E. Tasciotti, Bio-inspired engineering of cell- and virus-like nanoparticles for drug delivery, Biomaterials, 147 (2017) 155-168.

[14] A. Goes, G. Fuhrmann, Biogenic and biomimetic carriers as versatile transporters to treat infections, ACS Infectious Diseases, 4 (2018) 881-892.

[15] J.-W. Yoo, D.J. Irvine, D.E. Discher, S. Mitragotri, Bio-inspired, bioengineered and biomimetic drug delivery carriers, Nat Rev Drug Discov, 10 (2011) 521-535.

[16] H. Zhang, D. Freitas, H.S. Kim, K. Fabijanic, Z. Li, H. Chen, M.T. Mark, H. Molina, A.B. Martin, L. Bojmar, J. Fang, S. Rampersaud, A. Hoshino, I. Matei, C.M. Kenific, M. Nakajima, A.P. Mutvei, P. Sansone, W. Buehring, H. Wang, J.P. Jimenez, L. Cohen-Gould, N. Paknejad, M. Brendel, K. Manova-Todorova, A. Magalhães, J.A. Ferreira, H. Osório, A.M. Silva, A. Massey, J.R. CubillosRuiz, G. Galletti, P. Giannakakou, A.M. Cuervo, J. Blenis, R. Schwartz, M.S. Brady, H. Peinado, J. Bromberg, H. Matsui, C.A. Reis, D. Lyden, Identification of distinct nanoparticles and subsets of extracellular vesicles by asymmetric flow field-flow fractionation, Nat. Cell Biol., 20 (2018) 332-343.

[17] J.P.K. Armstrong, M.N. Holme, M.M. Stevens, Re-Engineering Extracellular Vesicles as Smart Nanoscale Therapeutics, ACS Nano, 11 (2017) 69-83.

[18] H. Zhang, T. Deng, R. Liu, M. Bai, L. Zhou, X. Wang, S. Li, X. Wang, H. Yang, J. Li, T. Ning, D. Huang, H. Li, L. Zhang, G. Ying, Y. Ba, Exosome-delivered EGFR regulates liver microenvironment to promote gastric cancer liver metastasis, Nature Communications, 8 (2017) 15016.

[19] D. Yuan, Y. Zhao, W.A. Banks, K.M. Bullock, M. Haney, E. Batrakova, A.V. Kabanov, Macrophage exosomes as natural nanocarriers for protein delivery to inflamed brain, Biomaterials, $142(2017) 1-12$. 
[20] D.S. Sutaria, J. Jiang, O.A. Elgamal, S.M. Pomeroy, M. Badawi, X. Zhu, R. Pavlovicz, A.C.P. Azevedo-Pouly, J. Chalmers, C. Li, M.A. Phelps, T.D. Schmittgen, Low active loading of cargo into engineered extracellular vesicles results in inefficient miRNA mimic delivery, J Extracell Vesicles, 6 (2017) 1333882.

[21] G. Fuhrmann, A.L. Neuer, I.K. Herrmann, Extracellular vesicles - A promising avenue for the detection and treatment of infectious diseases?, Eur. J. Pharm. Biopharm., 118 (2017) 56-61.

[22] G. Fuhrmann, I. Herrmann, M.M. Stevens, Cell-derived vesicles for drug therapy and diagnostics: opportunities and challenges, Nano Today, 10 (2015) 397-409.

[23] M.I. Ramirez, M.G. Amorim, C. Gadelha, I. Milic, J.A. Welsh, V.M. Freitas, M. Nawaz, N. Akbar, Y. Couch, L. Makin, F. Cooke, A.L. Vettore, P.X. Batista, R. Freezor, J.A. Pezuk, L. RosaFernandes, A.C.O. Carreira, A. Devitt, L. Jacobs, I.T. Silva, G. Coakley, D.N. Nunes, D. Carter, G. Palmisano, E. Dias-Neto, Technical challenges of working with extracellular vesicles, Nanoscale, 10 (2018) 881-906.

[24] L. Brown, J.M. Wolf, R. Prados-Rosales, A. Casadevall, Through the wall: extracellular vesicles in Gram-positive bacteria, mycobacteria and fungi, Nat Rev Micro, advance online publication (2015).

[25] A. Kulp, M.J. Kuehn, Biological Functions and Biogenesis of Secreted Bacterial Outer Membrane Vesicles, Annu. Rev. Microbiol., 64 (2010) 163-184.

[26] J. Berleman, M. Auer, The role of bacterial outer membrane vesicles for intra- and interspecies delivery, Environ. Microbiol., 15 (2013) 347-354.

[27] H. Yonezawa, T. Osaki, S. Kurata, M. Fukuda, H. Kawakami, K. Ochiai, T. Hanawa, S. Kamiya, Outer Membrane Vesicles of Helicobacter pylori TK1402 are Involved in Biofilm Formation, BMC Microbiol., 9 (2009) 197.

[28] L.M. Mashburn, M. Whiteley, Membrane vesicles traffic signals and facilitate group activities in a prokaryote, Nature, 437 (2005) 422-425.

[29] M. Kaparakis-Liaskos, R.L. Ferrero, Immune modulation by bacterial outer membrane vesicles, Nat Rev Immunol, 15 (2015) 375-387.

[30] K. Watanabe, Bacterial membrane vesicles (MVs): novel tools as nature- and nano-carriers for immunogenic antigen, enzyme support, and drug delivery, Appl. Microbiol. Biotechnol., 100 (2016) 9837-9843.

[31] V. Gujrati, S. Kim, S.H. Kim, J.J. Min, H.E. Choy, S.C. Kim, S. Jon, Bioengineered Bacterial Outer Membrane Vesicles as Cell-Specific Drug-Delivery Vehicles for Cancer Therapy, ACS Nano, 8 (2014) 1525-1537.

[32] I. Olsen, A. Amano, Outer membrane vesicles - offensive weapons or good Samaritans?, Journal of Oral Microbiology, 7 (2015) 10.3402/jom.v3407.27468.

[33] J.L. Kadurugamuwa, T.J. Beveridge, Bacteriolytic effect of membrane vesicles from Pseudomonas aeruginosa on other bacteria including pathogens, J. Bacteriol., 178 (1996) 2767-2774.

[34] Z. Li, A.J. Clarke, T.J. Beveridge, Gram-Negative Bacteria Produce Membrane Vesicles Which Are Capable of Killing Other Bacteria, J. Bacteriol., 180 (1998) 5478-5483.

[35] D.E. Whitworth, Chapter 1 - Myxobacterial Vesicles: Death at a Distance?, in: S.S. Allen I. Laskin, M.G. Geoffrey (Eds.) Adv. Appl. Microbiol., Academic Press, 2011, pp. 1-31.

[36] T. Hoffmann, D. Krug, N. Bozkurt, S. Duddela, R. Jansen, R. Garcia, K. Gerth, H. Steinmetz, R. Müller, Correlating chemical diversity with taxonomic distance for discovery of natural products in myxobacteria, Nature Communications, 9 (2018) 803.

[37] J.E. Berleman, J.R. Kirby, Deciphering the hunting strategy of a bacterial wolfpack, FEMS Microbiol. Rev., 33 (2009) 942-957.

[38] B. Norén, K.B. Raper, Antibiotic activity of Myxobacteria in relation to their bacteriolytic capacity, J. Bacteriol., 84 (1962) 157-162.

[39] B.S. Goldman, W.C. Nierman, D. Kaiser, S.C. Slater, A.S. Durkin, J.A. Eisen, C.M. Ronning, W.B. Barbazuk, M. Blanchard, C. Field, C. Halling, G. Hinkle, O. Iartchuk, H.S. Kim, C. Mackenzie, R. Madupu, N. Miller, A. Shvartsbeyn, S.A. Sullivan, M. Vaudin, R. Wiegand, H.B. Kaplan, Evolution of sensory complexity recorded in a myxobacterial genome, Proceedings of the National Academy of Sciences, 103 (2006) 15200-15205.

[40] A.G.L. Evans, H.M. Davey, A. Cookson, H. Currinn, G. Cooke-Fox, P.J. Stanczyk, D.E. Whitworth, Predatory activity of Myxococcus xanthus outer-membrane vesicles and properties of their hydrolase cargo, Microbiology, 158 (2012) 2742-2752. 
[41] G. Fuhrmann, R. Chandrawati, P.A. Pamar, T.J. Keane, S.A. Maynard, S. Bertazzo, M.M. Stevens, Engineering extracellular vesicles with the tools of enzyme prodrug therapy, Advanced Materials, 30 (2018) 1706616.

[42] J. Frank, M. Richter, C. De Rossi, C.-M. Lehr, K. Fuhrmann, G. Fuhrmann, Extracellular vesicles protect glucuronidase model enzymes during freeze-drying, Scientific Reports, 8 (2018) 12377.

[43] G. Fuhrmann, A. Serio, M. Mazo, R. Nair, M.M. Stevens, Active loading into extracellular vesicles significantly improves the cellular uptake and photodynamic effect of porphyrins, J. Control. Release, 205 (2015) 35-44.

[44] D. Danino, Cryo-TEM of soft molecular assemblies, Curr Opin Colloid Interface Sci, 17 (2012) 316-329.

[45] C. Pérez-Cruz, L. Delgado, C. López-Iglesias, E. Mercade, Outer-Inner Membrane Vesicles Naturally Secreted by Gram-Negative Pathogenic Bacteria, PLOS ONE, 10 (2015) e0116896.

[46] L. Zhang, Z. Cao, Y. Li, J.-R. Ella-Menye, T. Bai, S. Jiang, Softer Zwitterionic Nanogels for Longer Circulation and Lower Splenic Accumulation, ACS Nano, 6 (2012) 6681-6686.

[47] Á.M. Lőrincz, C.I. Timár, K.A. Marosvári, D.S. Veres, L. Otrokocsi, Á. Kittel, E. Ligeti, Effect of storage on physical and functional properties of extracellular vesicles derived from neutrophilic granulocytes, J Extracell Vesicles, 3 (2014) 25465.

[48] K.W. Witwer, E.I. Buzás, L.T. Bemis, A. Bora, C. Lässer, J. Lötvall, E.N. Nolte-‘t Hoen, M.G. Piper, S. Sivaraman, J. Skog, C. Théry, M.H. Wauben, F. Hochberg, Standardization of sample collection, isolation and analysis methods in extracellular vesicle research, J Extracell Vesicles, 2 (2013) 20360.

[49] C. Arigita, W. Jiskoot, J. Westdijk, C. van Ingen, W.E. Hennink, D.J.A. Crommelin, G.F.A. Kersten, Stability of mono- and trivalent meningococcal outer membrane vesicle vaccines, Vaccine, 22 (2004) 629-642.

[50] E.K. Park, H.S. Jung, H.I. Yang, M.C. Yoo, C. Kim, K.S. Kim, Optimized THP-1 differentiation is required for the detection of responses to weak stimuli, Inflammation Res., 56 (2007) 45-50.

[51] M. Keck, N. Gisch, H. Moll, F.-J. Vorhölter, K. Gerth, U. Kahmann, M. Lissel, B. Lindner, K. Niehaus, O. Holst, Unusual Outer Membrane Lipid Composition of the Gram-negative, Lipopolysaccharide-lacking Myxobacterium Sorangium cellulosum So ce56, J. Biol. Chem., 286 (2011) 12850-12859.

[52] C. Ruiz, A. Ruiz-Bravo, G.A. De Cienfuegos, A. Ramos-Cormenzana, Immunomodulation by Myxospores of Myxococcus xanthus, Microbiology, 131 (1985) 2035-2039.

[53] C. Ruiz, A. Ruiz-Bravo, A. Ramos-Cormenzana, Endotoxin-like activities inMyxococcus xanthus, Curr. Microbiol., 15 (1987) 343-345.

[54] E.J. O'Donoghue, A.M. Krachler, Mechanisms of outer membrane vesicle entry into host cells, Cell. Microbiol., 18 (2016) 1508-1517.

[55] K. Forier, K. Raemdonck, S.C. De Smedt, J. Demeester, T. Coenye, K. Braeckmans, Lipid and polymer nanoparticles for drug delivery to bacterial biofilms, J. Control. Release, 190 (2014) 607-623.

[56] S. Baumann, J. Herrmann, R. Raju, H. Steinmetz, K.I. Mohr, S. Hüttel, K. Harmrolfs, M. Stadler, R. Müller, Cystobactamids: Myxobacterial Topoisomerase Inhibitors Exhibiting Potent Antibacterial Activity, Angewandte Chemie International Edition, 53 (2014) 14605-14609.

[57] S. Hüttel, G. Testolin, J. Herrmann, T. Planke, F. Gille, M. Moreno, M. Stadler, M. Brönstrup, A. Kirschning, R. Müller, Discovery and Total Synthesis of Natural Cystobactamid Derivatives with Superior Activity against Gram-Negative Pathogens, Angewandte Chemie International Edition, 56 (2017) 12760-12764.

[58] T. Bjarnsholt, O. Ciofu, S. Molin, M. Givskov, N. Hoiby, Applying insights from biofilm biology to drug development - can a new approach be developed?, Nat Rev Drug Discov, 12 (2013) 791-808.

[59] S.A.A. Kooijmans, L.A.L. Fliervoet, R. van der Meel, M.H.A.M. Fens, H.F.G. Heijnen, P.M.P. van Bergen en Henegouwen, P. Vader, R.M. Schiffelers, PEGylated and targeted extracellular vesicles display enhanced cell specificity and circulation time, J. Control. Release, 224 (2016) 77-85.

[60] K. Fuhrmann, G. Fuhrmann, Recent advances in oral delivery of macromolecular drugs and benefits of polymer conjugation, Curr Opin Colloid Interface Sci, 31 (2017) 67-74. 